E3S Web of Conferences 1, 09003 (2013)

DOI: $10.1051 / \mathrm{e} 3$ sconf/20130109003

(c) Owned by the authors, published by EDP Sciences, 2013

\title{
Extraction of Lead through Supported Liquid Membrane Using Triethanolamine/Cyclohexanone Carrier and $\mathrm{Na}_{2} \mathrm{SO}_{4}$ strippant
}

\author{
$\underline{\text { R. Gill }}^{1}$, N. Bukhari ${ }^{2}$, S. Safdar ${ }^{3}$ and S. M. Batool ${ }^{4}$ \\ ${ }^{1}$ Department of Environmental Sciences, Fatima Jinnah Women University, Rawalpindi 46000, Pakistan, \\ rohama_gill@hotmail.com \\ ${ }^{2}$ Department Of Chemistry, Quaid-i-Azam University, Islambad, 54000, Pakistan, naheedbukhari@yahoo.com \\ ${ }^{3}$ Department of Environmental Sciences, Fatima Jinnah Women University, Rawalpindi,46000, Pakistan \\ sumar.khan@hotmail.com \\ ${ }^{4}$ Department of Environmental Sciences, Fatima Jinnah Women University, Rawalpindi,46000, Pakistan \\ syedamadiha313@gmail.com
}

\begin{abstract}
Supported liquid membranes (SLM) have proved to be effective not only for removing but also for recovery of heavy metals from waste water. This work includes the study of separation and transport of $\mathrm{Pb}^{+2}$ ions through liquid membrane based on triethanolamine (TEA) in cyclohexanone supported in microporous polypropylene films. Therefore, this study aims to optimize the conditions for moving the $\mathrm{Pb}^{+2}$ ions against the concentration gradient, characterize the membrane by flux measurements, for their use in various industrial plants design to recover these ions. The effect of lead ion concentration, $\mathrm{HNO}_{3}$ in feed and TEA concentration in membrane has been studied. Optimized condition of transport of this metal ion is $1.0 \mathrm{M}$ acid concentration in the feed phase and $0.1 \mathrm{M} \mathrm{Na}_{2} \mathrm{SO}_{4}$ as the strippant when TEA concentration is $5.25 \mathrm{~mol} / \mathrm{dm}^{3}$ in the membrane, as the rationale of this study is to optimize the condition for the movement of lead ions from feed phase to strip phase and to recover metal ions from any industrial effluent and finally to characterize the membrane by determining the mobility and permeability of the complexed heavy metal ion to extract their respective metal ions.
\end{abstract}

Key words: Heavy metal, Lead extraction, Supported Liquid Membrane, Triethanolamine, Cyclohexanon

\section{Introduction}

As heavy metal pollution has rendered colossal damage to the urban environment therefore concerted efforts are underway in the field of separation science to develop artificial membranes for the removal and recovery of ionic and molecular species. Lead enters into the environment as domestic as well as industrial discard mainly due to smelting, automobiles and mining process. During the last decades the removal of heavy metals released from the industrial effluents is a major concern worldwide, as heavy metals are not biodegradable and tend to accumulate into the soft tissues in organism and cause numerous diseases as well as disorders (Dupler, 2001). Heavy metals including zinc, lead and chromium have a variety of applications in basic engineering work in paper and pulp industries While these metals are emitted into the environment by both natural and anthropogenic causes while the anthropogenic sources specifically include mining operations (Ahalya et al.,
2007). Interestingly, small amounts of these heavy metals are common in our environment and diet and in fact permitted limit are vital for good health (Hutton and Symon, 1986). Lead is a poisonous toxic metal and it is a cause of most of pediatric heavy metal poisoning apart from beimg excessively used in pipes, and soldering materials. Liquid membrane technology is now used in a wide variety of separations in comparison to conventional separation processes as it sufficient to get high selectivity and also the use of energy and material is efficient. In this technique an organic liquid is immobilized in micro porous membrane that is placed between two solutions. At the boundary of the feed solution and the membrane, the solute is moved to the membrane liquid; which then moves by itself in a forming a complex to the farther side of the SLM, i.e the strippant (Chimuka et al.,2004). Membrane separation technology involves separation of organic, inorganic and suspended matters, which are often present simultaneously and is used in many industries like metal plating industry, micro-electronics 
industry, pharmaceutical industries and food and beverages industries to provide high quality products. This technique is also useful for gas separation process (Abedini and Nezhadmoghadam, 2010).Previously the removal of $\mathrm{Cr}$ (III), Co (II), and $\mathrm{Ni}$ (II) has been studied in a similar system. The prime aim of this effort was to optimize the conditions for the removal $\mathrm{Pb}$ (II) using the TEA-cyclohexanone support (Bukhari et al., 2004, 2006, 2007).

\section{Materials and Methods}

Triethanolamine, TEA (99.5\% pure), Cyclohexanone, $\mathrm{C}_{6} \mathrm{H}_{10} \mathrm{O}(99 \%)$ and $\mathrm{HNO}_{3}(65 \%)$ were obtained from Merck, while Lead nitrate $\mathrm{Pb}\left(\mathrm{NO}_{3}\right)_{2}$, was obtained from BDH chemicals. $\mathrm{Na}_{2} \mathrm{SO}_{4}$ was obtained from Sigma-Aldrich respectively. A tomic absorption spectrophotometer- Varian 220, was used for the quantitative measurement of $\mathrm{Pb}^{+2}$ ions in aqueous phases. $1 \mathrm{~mL}$ samples was drawn out from the feed and stripping phase after regular time interval for the analysis and diluted in $25.0 \mathrm{~mL}$ volumetric flask. A calibration curve was plotted by measuring the absorbance of different concentrations of $\mathrm{Pb}^{+2}$ ions solutions at wavelength, $217 \mathrm{~nm}$.. All the experiments were performed at ambient temperature in a batch type Perspex permeator (cell), which has two compartments of cubic shape, each of $250 \mathrm{~cm}^{3}$ capacity and fixed with controlled electrical stirrers.Membrane area was $14.72 \mathrm{~cm}^{2}$. A $1000 \mathrm{ppm}$ solution of $\mathrm{Pb}\left(\mathrm{NO}_{3}\right)_{2}$ was prepared in $\mathrm{HNO}_{3}$. This stock solution was then diluted to $300 \mathrm{ppm}$ and was used in feed phase. In the strip phase $0.1 \mathrm{M}$. $\mathrm{NaOH}$ was used separately in order to compare their ability for the mass transfer of proton. The organic phase or membrane phase was prepared by dissolving TEA/ cyclohexanone in various ratios i.e., 50:50, 30:70 and 70:30. The effect of extractant/ diluent concentration and the effect of acid concentration on transport of $\mathrm{Pb}$ (II) ion was studied systematically.Flux measurement was also achieved for the $\mathrm{Pb}^{+2}$ ions transport $\mathrm{NaOH}$ strippant by using the following formula:

$$
\mathrm{J}=\frac{C i-C f}{t} \times \frac{V}{A}
$$

$\mathrm{J}=$ Flux $\mathrm{mol} / \mathrm{m}^{2} . \mathrm{s}$

$\mathrm{C}_{\mathrm{i}}=$ Initial concentration of lead in feed phase $\left(\mathrm{mol} / \mathrm{dm}^{3}\right)$

$\mathrm{C}_{\mathrm{f}}=$ Final concentration of lead in feed phase

$\left(\mathrm{mol} / \mathrm{dm}^{3}\right)$

$\mathrm{t}=$ total time given to the cell for lead ions extraction

(sec)

$\mathrm{V}=$ Total volume of solution in feed phase. $\left(\mathrm{dm}^{3}\right)$

$\mathrm{A}=$ Area of the membrane $\left(\mathrm{m}^{2}\right)$

The mechanism of supported liquid membrane is based on diffusion process in which metal ions are transported from proton rich phase to another phase, therofore it can be presumed that the $\mathrm{Pb}^{+2}$ ions in feed phase form a complex with the TEA present as extractant in the organic membrane at the interface:

$\mathrm{M}^{2+}+2(\mathrm{HA})_{2} \rightarrow \mathrm{MA}_{2}(\mathrm{HA})_{2}+2 \mathrm{H}^{+}$
The complex of metal-extractant thus formed diffuses from this interface to the subsequent interface of organic phase and strippant, which can be as follows:

$\mathrm{MA}_{2}(\mathrm{HA})_{2}+2 \mathrm{H}^{+} \rightarrow \mathrm{M}^{2+}+2(\mathrm{HA})_{2}$

This phenomenon is known as facilitated transport as the ions of given metal are passed on by the extractant to smooth and to some extent expedite the progress of transport across the SLM .

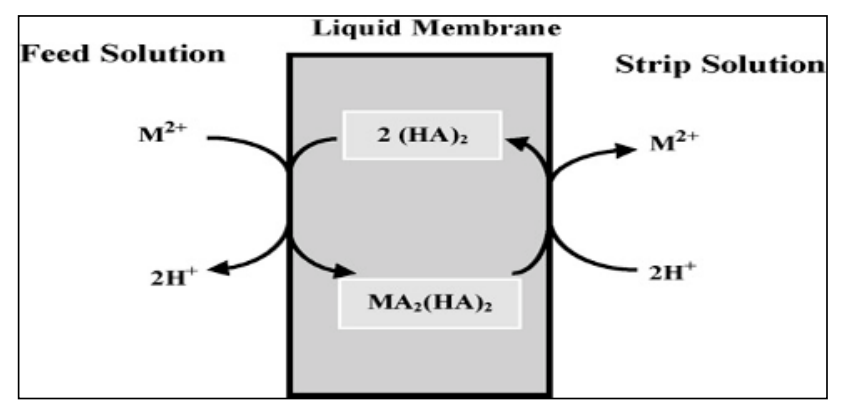

Proposed Mechanism of mass transfer in SLM

\section{Results and Discussion}

In SLM extraction of selected species are extracted from an aqueous phase in the pores hold the organic liquid. Nevertheless, the shortcoming of liquid membrane extraction can be decrease in flux and selectivity loss to some extent. Liquid membrane extractions is growingly considered as a substitute of usual sample preparation procedures for analysing chemical species present in biological and environmental samples. In the present work lead ion extraction from its solution was monitored over a period of time through a SLM. As there are a number of parameters on which these extraction depends such as the concentration of the metal ion, concentration and ratio between the extractant and diluent and the nature and concentration of the strippant, therefore $\mathrm{Pb}^{+2}$, (TEA/ cyclohexanone), $\mathrm{Na}_{2} \mathrm{SO}_{4}$ were used as metal to be extracted, carrier/diluent, and strippant, respectively.A series of experiment was carried out to observe the transport of lead ion concentration and the factors considered are the effect of TEA by taking three different ratios of extractant and the diluent and also effect of different concentration of acid in feed on metal ion transport.

\section{Effect of Acid concentration in feed phase}

This factor, as given in Fig.1 illustrates effect of varying acid concentration in feed phase on the transport of lead ions, depicting the decrease of $\mathrm{Pb}^{+2}$ ion concentration in the feed phase whereas increase in its concentration in the strip phase with time. As expected, these graphs shows the relation of $\mathrm{Pb}^{+2}$ transport with the different concentration of $\mathrm{HNO}_{3}$ that is used in the feed phase for the protonation and it has been observed that increase in the acid concentration of feed solution augments the transport of lead ions but it is more obvious from the figures that the permeability of lead ion initially increases 
with increased acid concentration, passes through a maximum value and ultimately decreasing (Bukhari et al,2004). Fig.1 shows the transport of lead ion when $0.1 \mathrm{M}$ acid is used in the feed phase with varying TEA concentration of 2.252, 3.75, $5.25 \mathrm{~mol} / \mathrm{dm}^{3}$ by adjusting the TEA/diluent ratio at 30:70, 50:50 and 70:30 respectively. It has been observed that when the acid concentration is $0.1 \mathrm{M}$ in feed phase and TEA concentration is $2.25 \mathrm{~mol} / \mathrm{dm}^{3}$ in the membrane more lead ion has been extracted.

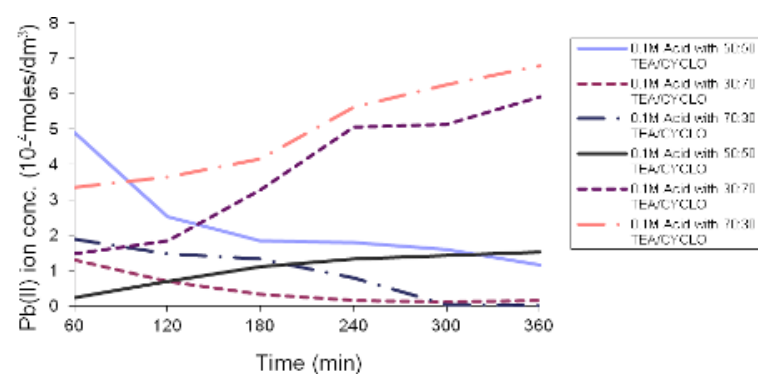

Fig. 1.Variation in $\mathrm{Pb}^{+2}$ ion concentrations in feed and strip versus time at $0.1 \mathrm{M} \mathrm{HNO}_{3}$ concentration in feed. Initial $\mathrm{Pb}^{+2}$ conc.in feed $=9.057 \times 10^{-4}$. TEA concentration $=3.75 \mathrm{~mol} / \mathrm{dm}^{3}, 2.252 \mathrm{~mol} / \mathrm{dm}^{3}, 5.25 \mathrm{~mol} /$ $\mathrm{dm}^{3}$

Fig. 2 shows the transport of lead ion when $0.5 \mathrm{M}$ acid is used in the feed phase with different TEA concentration the AAS analysis of the feed and strippant after equal time intervals revealed that when the acid concentration is $0.5 \mathrm{M}$ in feed phase and TEA concentration is 3.75 $\mathrm{mol} / \mathrm{dm}^{3}$ in the membrane more lead ion has been extracted as shown.Thus it can been predicted that with $0.5 \mathrm{M}$ acid concentration in the feed and $3.75 \mathrm{~mol} / \mathrm{dm}^{3}$ TEA concentration in the membrane more lead ion can be extracted across the membrane.

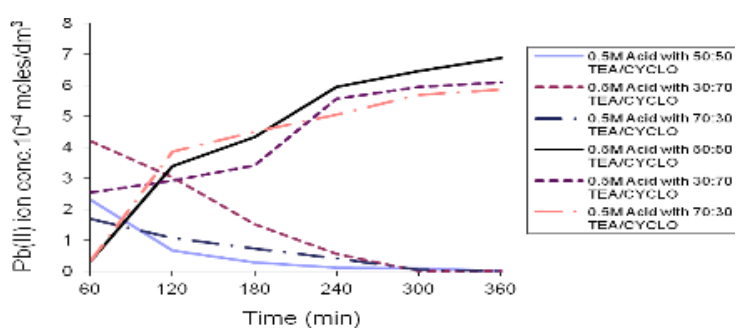

Fig. 2. Variation in $\mathrm{Pb}^{+2}$ ion concentrations in feed and strip versus time at $0.5 \mathrm{M} \mathrm{HNO}_{3}$ concentration in feed. Initial $\mathrm{Pb}^{+2}$ conc.in feed $=9.057 \times 10^{-4}$. TEA concentration $=3.75 \mathrm{~mol} / \mathrm{dm}^{3}, 2.252 \mathrm{~mol} / \mathrm{dm}^{3}, 5.25 \mathrm{~mol} /$ $\mathrm{dm}^{3}$

The transport of lead ion when 1.0 M acid is used in the feed phase with different TEA concentration (Fig.3), and it has been observed that when the acid concentration is $1.0 \mathrm{M}$ in feed phase and TEA concentration is 5.25 $\mathrm{mol} / \mathrm{dm}^{3}$ in the membrane more lead ion has been extracted as shown. Fig. 3 indicates the $\mathrm{Pb}^{+2}$ ion transport with $1.0 \mathrm{M}$ acid concentration in the feed phase. Amount of protons and the $\mathrm{pH}$ value in feed phase is fundamental factor onto which the trasportation course of $\mathrm{Pb}^{+2}$ ions in the feed phase of the liquid membrane depends. This can be attributed to the increased $\mathrm{pH}$ values of the feed side as noted after regular time intrevals

( Bukhari et al.,2004)

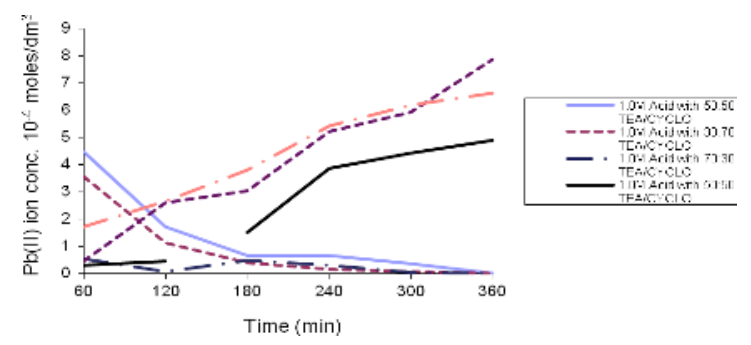

Fig. 3. Variation in $\mathrm{Pb}^{+2}$ ion concentrations in feed and strip versus time at $1.0 \mathrm{M} \mathrm{HNO}_{3}$ concentration in feed. Initial $\mathrm{Pb}^{+2}$ conc.in feed $=9.057 \times 10^{-4}$. TEA concentration $=3.75 \mathrm{~mol} / \mathrm{dm}^{3}, 2.252 \mathrm{~mol} / \mathrm{dm}^{3}, 5.25 \mathrm{~mol} /$ $\mathrm{dm}^{3}$

Since $\mathrm{H}^{+}$ions are responsible for formation of a metal complex with carrier molecule so these three protons are consumed from the feed side thereby increasing the $\mathrm{pH}$ of feed side. As the acid concentration decreases on the feed side the amount of acid decreases with time when initial concentration of acid in feed is taken $0.1 \mathrm{M}$ i.e. the rate of metal ion extraction decreases as shown in the Figs. (1-3). Consequently, with $1.0 \mathrm{M}$ acid concentration with 5.25 $\mathrm{mol} / \mathrm{dm}^{3}$ TEA concentration it has been seen that more lead ions can be extracted

\section{Effect of TEA Concentration on Feed Phase}

An assortment of triethanolamine extractant concentration taken in the liquid membrane shown in the Figures 4-6. These figures indicate the decrease in feed concentration of $\mathrm{Pb}^{+2}$ ions at regular time intervals. Fig.4 shows the permeation of $\mathrm{Pb}^{+2}$ ions through membrane having three different TEA concentrations at $0.1 \mathrm{M}$ acid concentration.

It can be predicted from the figures 5 and 6 that with the increase in TEA concentration the permeability of lead ion increases to a maximum value but with further increase in TEA concentration the permeability decreases and this may be attributed the rate of formation of complex and their extraction in the membrane phase.

Increase in TEA concentration will lead to more $\mathrm{Pb}^{+2}$-TEA complex formation thus it increases is concentration gradient within the membrane. This may increase the thickness of the membrane along with the viscosity of the membrane phase resulting into the decrease in $\mathrm{Pb}^{+2}$ ion transport.

TEA concentration raise in the membrane is expected to increase the transport of lead ions with greater speed but the viscosity increase in the liquid membrane phase enhances the friction for metal ion complex and so has an adverse effect on the permeability (Bukhari et al., 2007). Therefore, TEA concentration 
impedes the flow rate of lead carrier complex. The efficient transport of lead ion is found when the ratio of carrier concentration is $5.25 \mathrm{~mol} / \mathrm{dm}^{3}$ because in this case the diffusion rate of complex formation is maximum and due to which the transport of lead ion is maximum. It has been observed that the change in concentration and nature of the strippant greatly influence the amount of metal that finally reaches the stripping phase.

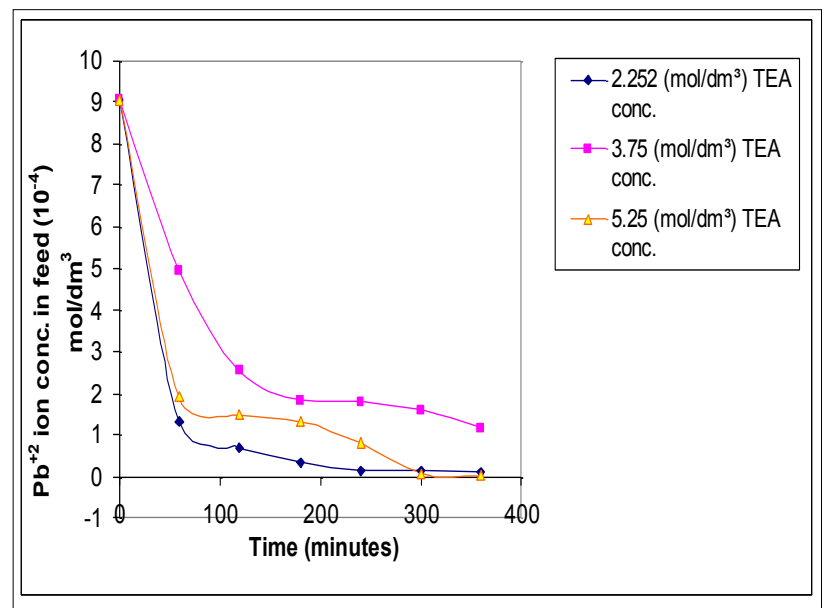

Fig. 4. Variation in $\mathrm{Pb}^{+2}$ ion concentrations in feed phase as a function of TEA conc.at $0.1 \mathrm{M} \mathrm{HNO}_{3}$

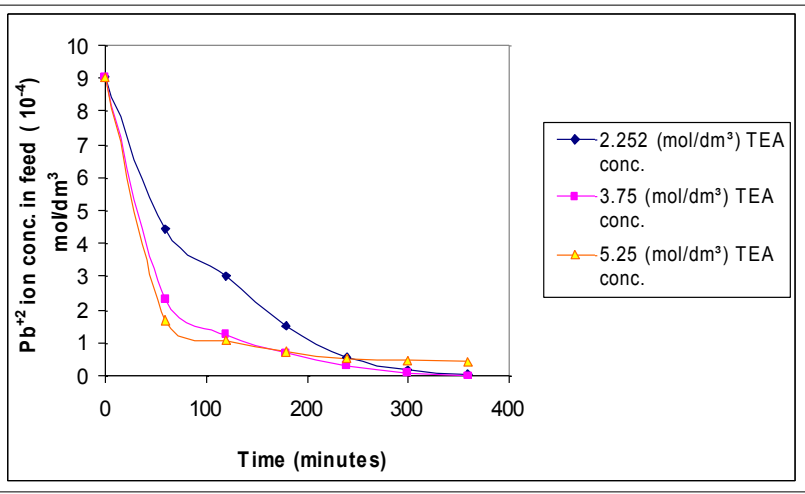

Fig. 5. Variation in $\mathrm{Pb}+2$ ion concentrations in feed phase as a function of TEA conc.at $0.5 \mathrm{M} \mathrm{HNO}_{3}$

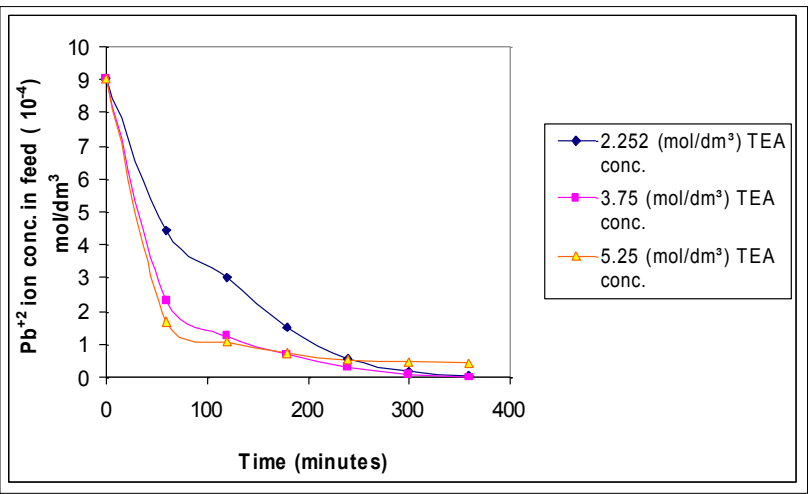

Fig. 6. Variation in $\mathrm{Pb}^{+2}$ ion concentrations in feed phase as function of TEA concentration at $1 \mathrm{M} \mathrm{HNO}_{3}$
In the present study $0.1 \mathrm{M}$ aqueous solution of $\mathrm{Na}_{2} \mathrm{SO}_{4}$ was used in the stripping phase. Although $\mathrm{Na}_{2} \mathrm{SO}_{4}$ proved to be a good strippant especialy in case when $\mathrm{Pb}$ ion solution was prepared in $1.0 \mathrm{M} \mathrm{HNO}_{3}$ and ratio between the extractant and diluent in the SLM was 70:30, as depicted in the figures 4-6. The amount of $\mathrm{Pb}^{+2}$ ion recovered in the stripping phase is not exactly the same amount as that lost in the feed phase in each case, which can be attributed to the fact that some $\mathrm{PbSO}_{4}$ thus formed in the strippant is remains undissloved and attaches to the walls of the cell due to high $\mathrm{Ksp}$ of $\mathrm{PbSO}_{4}$ in aqueous medium.

\section{Measurement of Flux for the Transport of $\mathrm{Pb}^{+2}$}

The flux of $\mathrm{Pb}^{+2}$ ion through the TEA/cyclohexanone SLM, increases with increase in TEA concentration in the liquid membrane as shown in previous studies of Bukhari et.al.. The rate of complex formation and decrease in the transport of $\mathrm{Pb}$ (II) ion support this observation. The viscosity increases in the membrane which boosts up the friction for lead ions complex and thus impeding the flux $(\mathrm{J})$. At low concentration of acid $(0.1 \mathrm{M})$ in feed, flux increases only when the TEA concentration in membrane phase is more but drops drastically when concentration the TEA concentration decreases.

\section{Conclusion}

SLM in comparison with other separation techniques is effective and economical technique and it is a single step technique for the separation or extraction of different metal ions. The present study aimed at extracting and transporting $\mathrm{Pb}+2$ ion and $99.94 \%$ metal ions was extracted across the membrane when $0.5 \mathrm{M}$ acid concentration was used in the feed phase with 3.75 $\mathrm{mol} / \mathrm{dm}^{3}$ TEA concentration in the membrane phase. Similarly with $2.25 \mathrm{~mol} / \mathrm{dm}^{3}$ TEA concentration and $0.1 \mathrm{M}$ acid concentration in feed phase maximum metal ion was extracted. Optimum condition for the metal extraction in this study was $1.0 \mathrm{M}$ acid concentration with $5.25 \mathrm{~mol} / \mathrm{dm}^{3}$ TEA concentration in the membrane phase Strippant concentration was fixed and the effect of different acid concentration in feed phase was observed to extract metal ions. Similarly other metal ions can be extracted using the same or different extractant in membrane, different acid in the feed phase and different strippant.Presently we are studying the effect of $\mathrm{NaOH}$ as a potential strippant to compare it with $\mathrm{Na}_{2} \mathrm{SO}_{4}$ strippant.

\section{Acknowledgements}

RG is grateful to the Higher Education Commission Pakistan for the financial support to participate in the ICHMET 2012 in Rome, Italy.

\section{References}

Abedini R, Nezhadmoghadam A.Application of Membrane in gas separation processes, Journal of petroleum and Coal.2010; 52: 69-80. 
Ahalya N, Ramachandra TV and Kanamadi RD. Biosorption of Heavy Metals. Res. J. Chem. Environ. Dec, 2003; 7.

Bukhari N, Chaudry MA, Mazhar M. Mechanism of cobalt,(II),transport,through,triethanolamine cyclohexanone supported liquid membranes, Journal of Membrane. Science. 2004; 234: 157-165.

Bukhari N, Chaudry A, M.Mazhar M.Triethanolamine-cyclohexanone supported liquid membranes study for extraction and removal of nickel ions from nickel plating wastes, Jouranl of Membrane Science.2006;283: 182-189.

Chaudry M.A, Bukhari N, Mazhar M, Abbasi W.Coupled transport of chromium(III) ions across triethanolamine/ cyclohexanone based supported liquid membranes for tannery waste treatment Separation And Purification Technology. 2007;55: 292-299.

Chimuka L, Cukrowska E, Åke Jönsson J. Why Liquid membrane extraction is an attractive alternative in sample preparation. Journal of Pure Applied Chemistry, 2004; 76:707-722.

Dupler D. Heavy Metal Poisoning. Grade Encyclopedia of alternative medicine. Farmington Hills, I: Gale group, 2001.

Hutton M, Symon C. The Quantities of Cadmium, Lead, Mercury and Arsenic Entering the U.K. Environment from Human Activities. Sci. Total Environ. 1986; 57:129-150.

Husseinzadeh D. Selective and Facilitated Transport of Vanadium $(\mathrm{VO} 2+)$ Ion through Supported Liquid Membrane and Effects of Membrane Characteristics. World academy of sciences, Engineering and Technology. 2010; 71.

Winston Ho WS, Wang B, Neumuller TE, Roller J. Supported liquid membrane for the removal and recovery of metals from waste waters and process streams: Environmental progress. 2001; 20: 11. 